\title{
ILIZAROV RING FIXATOR IN THE MANAGEMENT OF INFECTED NONUNION OF TIBIA - A CLINICAL STUDY
}

\author{
Dennis Antony ${ }^{1}$, Rajany Jose ${ }^{2}$ \\ ${ }_{1}^{1}$ Assistant Professor, Department of Orthopaedics, Government Medical College, Thrissur, Kerala. \\ ${ }^{2}$ Assistant Professor, Department of Community Medicine, Government Medical College, Thrissur, Kerala.
}

\begin{tabular}{l}
\hline ABSTRACT \\
\hline BACKGROUND \\
Infected non-union of bones is a challenging problem. Professor G A Ilizarov from Russia developed a circular external skeletal fixator \\
to attain union. Numerous studies have described its use in infected non-union management. However, very few studies were \\
available on this from India. \\
$\quad$ Aim of this study is to evaluate the functional outcome of infected non-union of tibia managed by Ilizarov technique.
\end{tabular}

Aim of this study is to evaluate the functional outcome of infected non-union of tibia managed by Ilizarov technique.

\begin{abstract}
MATERIALS AND METHODS
A prospective study was done at Department of Orthopaedics, Government Medical College, Thiruvananthapuram on 25 patients who satisfied the inclusion criteria. The patients were subjected to a thorough clinical assessment followed by application of Ilizarov ring fixator. The results of the surgical procedure were analysed in terms of bone results and functional results. For assessing bone result, 4 criteria were evaluated - union, infection, deformity and leg length discrepancy. The end result was categorised as Excellent/Good/Fair/Poor. Functional results were assessed based on 5 criteria- inactivity, significant limp, equinus rigidity of ankle, soft tissue dystrophy (skin hypersensitivity/insensitivity of sole or decubitus) and pain. The end result was categorised as Excellent/Good/Fair/ Poor. Outcome was expressed using mean and proportions as appropriate.
\end{abstract}

\section{RESULTS}

The mean age of the patients was $34.96+11.2$ years. Before the application of Ilizarov fixator, the duration of disability ranged from 3 months to 3 yrs. Union was achieved in all (92\%) except two patients. Residual bone deformity was seen in only 4 patients. On final analysis, bone result was found to be excellent in $36 \%$ and good in $28 \%$ of the patients while the functional result was reported excellent in $48 \%$ and good in 32\%. 18 patients developed pin-tract infections at some point of time during treatment which was managed effectively with antibiotics. At final followup, there were 5 patients who had residual equinus contracture.

\section{CONCLUSION}

Non-union presents a therapeutic challenge to the orthopaedic surgeon. It is thus concluded from our study that when traditional methods of managing these non-unions fail, Ilizarov technique provides excellent results for majority of the patients by allowing early function of the limb resulting in adequate stimulus for soft tissue and bone healing.

\section{KEYWORDS}

Infected Non-Union of Tibia, Ilizarov Technique, External Ring Fixation.

HOW TO CITE THIS ARTICLE: Antony D, Jose R. Ilizarov ring fixator in the management of infected nonunion of tibia - A clinical study. J. Evolution Med. Dent. Sci. 2016;5(92):6835-6841, DOI: 10.14260/Jemds/2016/1546

\section{BACKGROUND}

Infected non-union of bones is a challenging problem to orthopaedic surgeons. Since by definition, non-unions can only be diagnosed when at least six months have elapsed since the fracture and when there is evidence that union will not take place, infection under these conditions tend to become chronic often with multidrug resistant organisms. Infected non-unions bring together the problems of resistant bone infection and loss of stability of bone.

Financial or Other, Competing Interest: None.

Submission 06-10-2016, Peer Review 06-11-2016,

Acceptance 12-11-2016, Published 17-11-2016.

Corresponding Author:

Dennis Antony,

Assistant Professor

Department of Orthopaedics,

Government Medical College,

Thrissur,

Kerala.

E-mail: dennisantony@gmail.com

DOI: $10.14260 /$ jemds $/ 2016 / 1546$

\section{(c) (i) $(8)$}

The classical modalities of treatment of infected non-union range from prolonged immobilisation, aggressive surgical debridement followed by extensive reconstruction using bone graft and microvascular tissue transfer technique to electrical stimulation which had variable rates of success and included multiple extensive procedures with great blood loss, prolonged hospital stay, limited ability to correct limb length discrepancy and lack of early functional rehabilitation.

In 1950, professor G A Ilizarov from Russia, developed a circular external skeletal fixator which employed the principle of distraction osteogenesis to attain union, correct deformities and eradicate infection in infected non-union. Numerous studies.(1)(2)(3)(4) have described its use in infected non-union management. However, very few studies were available on this from India. This study was thus planned to evaluate the functional outcome of infected non-union of tibia managed by Ilizarov technique.

\section{MATERIALS AND METHODS}

A longitudinal descriptive study was conducted in the Department of Orthopaedics, Government Medical College, Thiruvananthapuram among 25 patients diagnosed to have 
infected non-union of tibia. The cases of infected non-union were identified using clinical criteria namely mobility at fracture-site, duration, presence of non-healing wound, radiological evidence of failed bony-union and microbiological evidence of polymicrobial multiresistant flora on doing culture from the discharging wound. The inclusion criteria included cases initially treated by internal fixation, dynamic compression plate, external fixator or plaster immobilisation. Elderly and patients with polytrauma and tumours were excluded from the study. Non-union was classified based on the Ilizarov system of classification for deciding treatment.

The cases were assessed pre-operatively, clinically, radiologically, and with the help of swab culture. Clinically, the mobility, signs of infection, soft tissue condition, limb-length discrepancy and adjacent joints were assessed. Radiologically, the status of bone-ends, the gap and amount of deformity, and signs of infection were noted. The wound was thoroughly irrigated with normal saline and a sterile swab was used to get specimen for culture and sensitivity from the non-healing wound. After obtaining clearance from the institutional ethical committee and informed written consent from the patients, a proforma was administered to collect information regarding sociodemographic variables like age, sex, occupation; grading of injury, mode of previous treatment, duration of disability and clinical examination was done to categorise the patients.

\section{Operative Procedure}

Under spinal anaesthesia, the infected non-union site was thoroughly debrided and the Ilizarov ring frame was applied maintaining the limb alignment. Ilizarov wires $(1.8 \mathrm{~mm})$ were passed first from the proximal fibula and then through the tibia parallel to the joint line (fig 1). The distal wire was passed from the lower third of fibula through the distal tibia and then secured using cannulated or slotted bolts depending on where the wire exits on the ring. Next, wires were passed near to the fracture site leaving a gap of $1.5 \mathrm{~cm}$ and secured to the frame. Then the wires were tensioned. Additional wires were inserted in the proximal most and distal most ring with a minimum of three wires in total. All wires were inserted based on the safe zone of the tibia. Additional wires were placed on the other rings with a minimum of two and a maximum of three wires.

In 4 cases, intramedullary wires were introduced entering from the medial malleolus to prevent translation of the bone segment during bone transport. Classical corticotomy was performed in our study. The average latency used in this study for distraction at corticotomy site was 5-7 days.

\section{Post-Operative Management}

The patients were advised partial weight bearing with the use of crutches as early as possible. Distraction was taught to the patient and his relatives and they were treated on an outpatient basis with fortnightly reviews. Cleaning of the rings and wires using Betadine and hydrogen peroxide was done by the patient. Any problems or obstacles that arose during treatment were managed accordingly.

\section{Frame Removal}

The healing time is short with the Ilizarov techniques as it is a biological method of healing. The nuts of the frame were loosened and the patient was allowed to walk in the frame. If the patient had no pain, he was allowed to ambulate in the dynamised frame for about a month. Then the frame was removed and a plaster of Paris cast was applied for about a month. Patients were periodically followed up for a minimum period of one year.

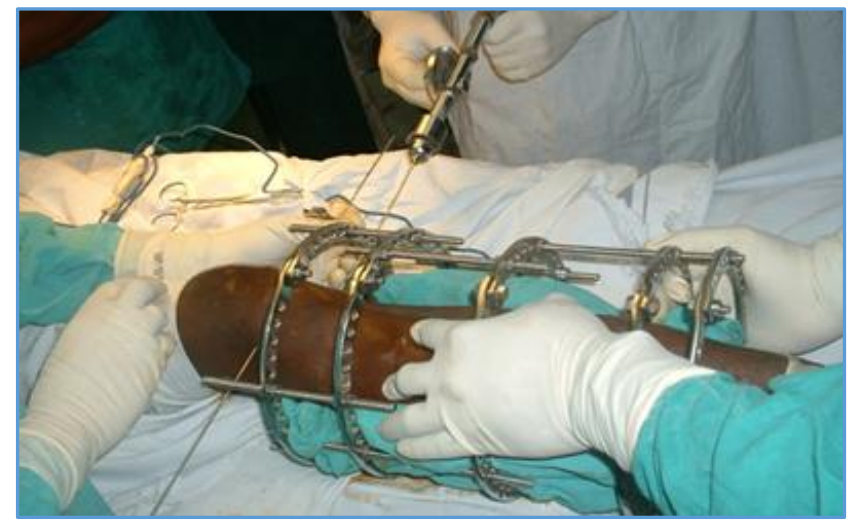

Figure 1

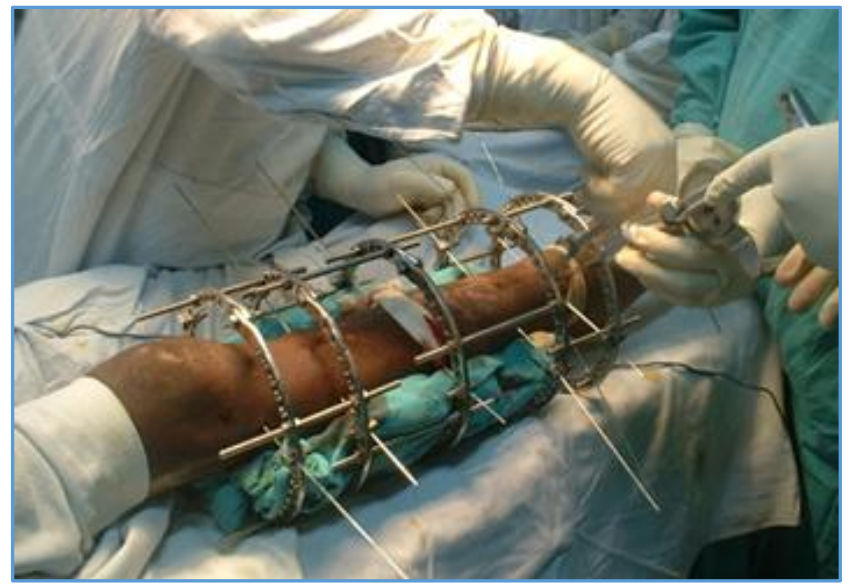

Figure 2

The data collected was entered into MS Excel software and analysed using Epi info 7 statistical software. The results were expressed in percentages.

The results of the surgical procedure were analysed in terms of bone results and functional results. For assessing bone result, 4 criteria were evaluated-union, infection, deformity and leg length discrepancy. The end result was categorised as Excellent/ Good/ Fair/Poor.

- Excellent: Union, no infection, Deformity <7 degrees, Leg length discrepancy $<2.5 \mathrm{~cm}$.

- Good: Union plus any two of the other criteria.

- Fair: Union plus any one of the other criteria.

- Poor: Non-union or re-fracture or union with none of the other criteria.

Functional results were assessed based on 5 criteriainactivity, significant limp, equinus rigidity of ankle, soft tissue dystrophy (skin hyper sensitivity/ insensitivity of sole or decubitus) and pain. The end result was categorised as Excellent/Good/Fair/Poor.

- Excellent: Active individual with none of the other four criteria.

- Good: Active individual with one or two of the other four criteria.

- Fair: Active individual with three or four of the other four criteria. 
- Poor: Active individual with poor result regardless of other criteria (active person with all the four criteria/inactive person regardless of other criteria).

\section{RESULTS}

This study was conducted in 25 cases of non-union of tibia in the Department of Orthopaedics, Medical College, Thiruvananthapuram. The mean age of the patients was 34.96 years with a standard deviation of 11.2 years (range 18 to 60 yrs.). Majority of patients belonged to 40-50 years age group (Fig 3). All patients except one were males.

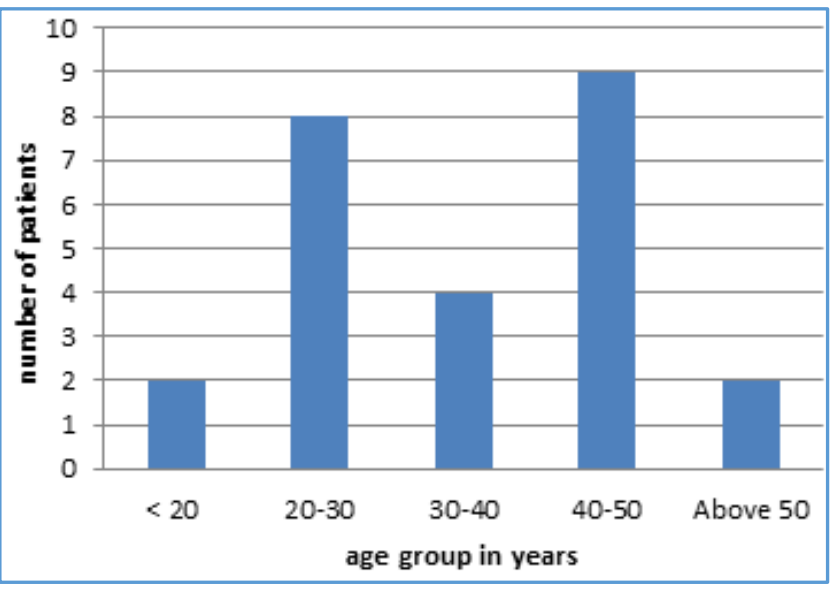

Figure 3. Age Distribution

All the 25 cases were the result of compound fractures. As per the Gustilo and Anderson grading, 17 (68\%) cases were type III and the rest were type II. All the cases had non-healing sinuses with a culture report of polymicrobial multiresistant flora. All patients had received unsuccessful treatment for their fractures before the Ilizarov technique was applied. 12 (48\%) cases had been treated by external fixators, 8 (32\%) cases by internal fixation either using intramedullary nails or with DCP and screws while the remaining were treated with long leg slab. The duration of disability ranged from 3 months to 3 yrs. before the application of Ilizarov fixator.

\begin{tabular}{|c|c|c|}
\hline Type & Number & Percentage \\
\hline Hypervascular & 20 & 80 \\
\hline Avascular & 5 & 20 \\
\hline \multicolumn{3}{|c|}{ Table 1. Distribution of Cases as per Weber and Cech } \\
Classification \\
\hline
\end{tabular}

\begin{tabular}{|c|c|c|}
\hline Type & Number & Percentage \\
\hline \multicolumn{2}{|c|}{ Type A (less than 1 cm bone loss) } \\
\hline A1 (lax) & 2 & 8 \\
\hline A2- 1 (Stiff, no deformity & Nil & Nil \\
\hline A2 -2 (fixed deformity) & 1 & 4 \\
\hline \multicolumn{2}{|c|}{ Type B (More than 1 cm bone loss) } \\
\hline B 1 (Bony defect, no shortening) & 5 & 20 \\
\hline B2 (Shortening, no defect) & 13 & 52 \\
\hline $\begin{array}{c}\text { B3 (Bony defect and } \\
\text { shortening) }\end{array}$ & 4 & 16 \\
\hline Total & $\mathbf{2 5}$ & $\mathbf{1 0 0}$ \\
\hline Table 2. Distribution of Cases as per Dror Paley et al \\
\hline
\end{tabular}

Table 2. Distribution of Cases as per Dror Paley et al
The mean duration of treatment with Ilizarov ring fixator for infected non-union of tibia was 33 weeks (range 12-60 weeks).

Union was achieved in all except two patients. One case of failure occurred in infected non-union tibia resulting from type III compound fracture both bones (distal $1 / 3^{\mathrm{rd}}$ ) that had been previously treated by external fixator and cross leg flap. Bone transport was done with the application of four ring assembly. After four months, eradication of infection was achieved and a minimal docking mal-alignment ( $10 \%$ contact) occurred. However, before achieving solid union, the fixator had to be removed on patient's demand due to noncompliance and then intramedullary fixation with fusion of ankle joint was done.

The other case of failure occurred in a case of infected nonunion resulting from a type IIIA compound fracture. He was previously treated with external fixator and split skin grafting. A four-ring assembly for bifocal osteosynthesis was applied. Infection was not eliminated even after three months. Culture results showed MRSA positive. Since the patient demanded removal of apparatus, the frame was removed and long leg cast was applied after which the patient became lost to followup. Infected non-unions were treated by debridement of infected bone and necrotic tissue and bifocal osteosynthesis and antibiotics. All of the 23 patients with successful outcome had eradication of infection at about halfway of the treatment.

In the final analysis, 4 patients had significant residual deformity measured radiologically but there was no significant functional impairment and all patients were able to use the limb well at the time of review. The true angle and plane of deformity was calculated from the true anteroposterior and lateral views as described by Dror Paley. Varus angulation and posterior angulation were given positive values; valgus angulation and anterior angulation were given negative values.

\section{Followup}

Duration of followup of the patients ranged from 3 months to 2 years. Two patients developed knee stiffness due to cutthrough of upper ring into knee joint. At the last followup, only the two failure cases required any orthotic aids. All successful cases returned to full-fledged daily activities and most are leading economically productive lives at present. Two patients had limb length discrepancy more than $1 \mathrm{~cm}$ which was acceptable to the patient.

\begin{tabular}{|c|c|c|c|}
\hline Modality & Yes/No & Frequency & $\%$ \\
\hline \multirow{2}{*}{ Union } & Yes & 23 & 92 \\
\cline { 2 - 4 } & No & 2 & 8 \\
\hline \multirow{2}{*}{ Infection } & Yes & 1 & 4 \\
\cline { 2 - 4 } & No & 24 & 96 \\
\hline \multirow{2}{*}{ Limb-Length discrepancy } & Yes & 2 & 8 \\
\cline { 2 - 4 } & No & 23 & 92 \\
\hline \multirow{2}{*}{ Radiological union } & Yes & 23 & 92 \\
\cline { 2 - 4 } & No & 2 & 8 \\
\hline \multirow{2}{*}{ Residual bone deformity } & Yes & 4 & 16 \\
\cline { 2 - 4 } & No & 21 & 84 \\
\hline \multicolumn{2}{|c|}{ Table 3. Status after Followup } \\
\hline
\end{tabular}

The final result grading is based on a total of 9 parameters which includes clinical, radiological and functional assessment of the patient, some of which are subjective and depends on patient's assessment. 


\begin{tabular}{|c|c|c|}
\hline \multicolumn{3}{|c|}{ Bone Result } \\
\hline Grade & Number & Percentage \\
\hline Excellent & 9 & 36 \\
\hline Good & 7 & 28 \\
\hline Fair & 6 & 24 \\
\hline Poor & 3 & 12 \\
\hline \multicolumn{3}{|c|}{ Functional result } \\
\hline Grade & Number & Percentage \\
\hline Excellent & 12 & 48 \\
\hline Good & 8 & 32 \\
\hline Fair & 3 & 12 \\
\hline Poor & 2 & 8 \\
\hline \multicolumn{2}{|c|}{ Table 4. Final Result Grading } \\
\hline
\end{tabular}

\section{CASE 1}

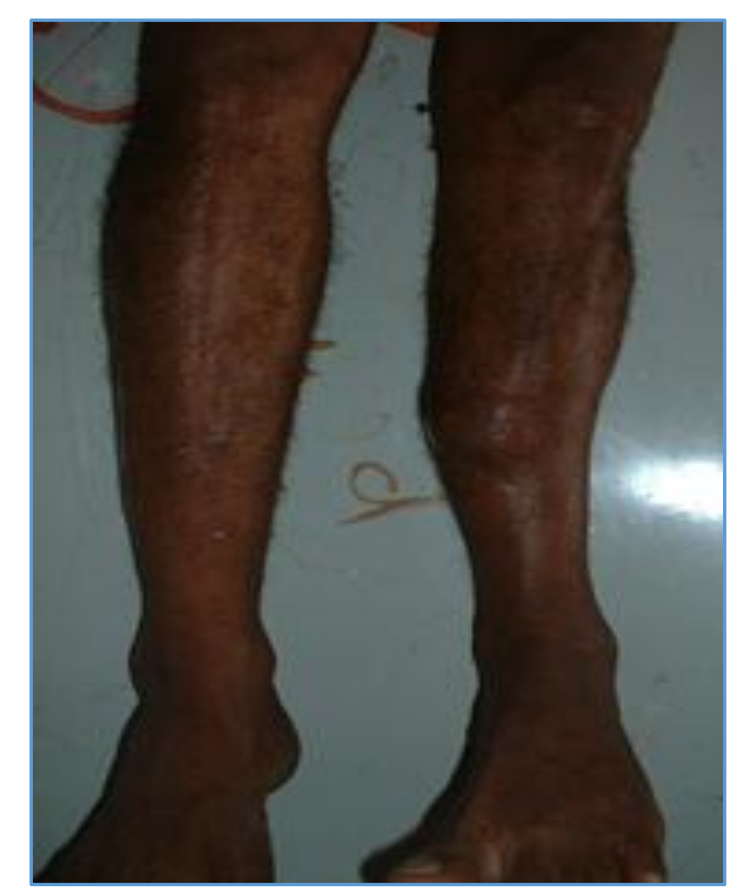

Pre - Op

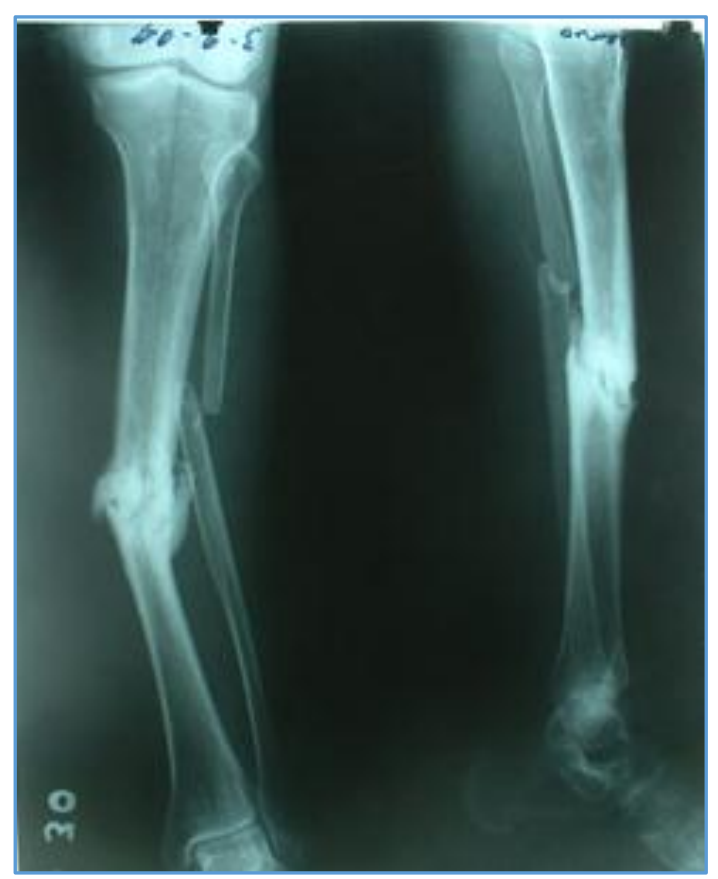

Pre-Op

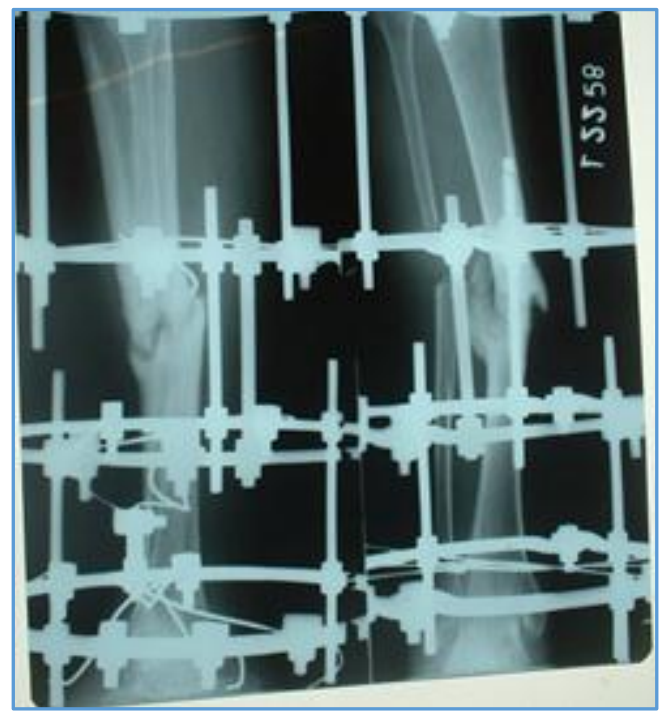

Post Op

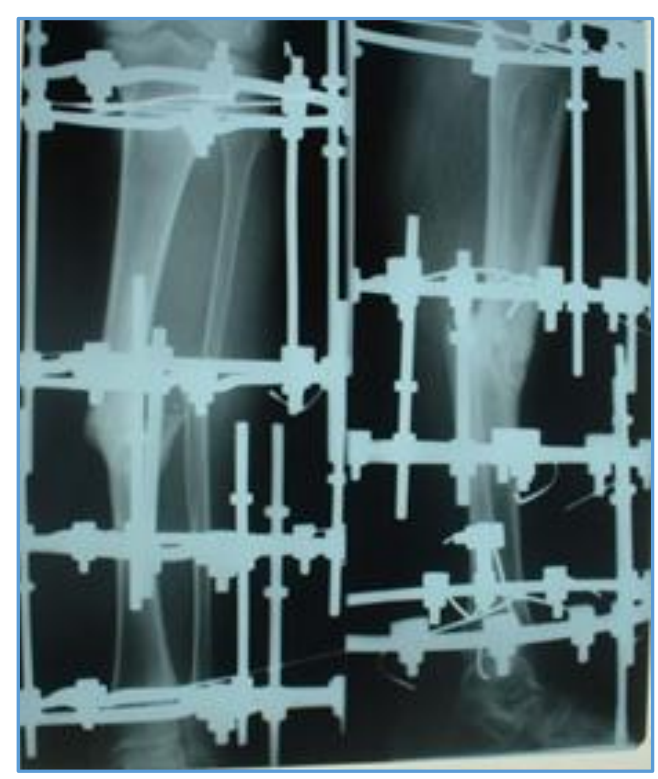

Fracture United

Case 2

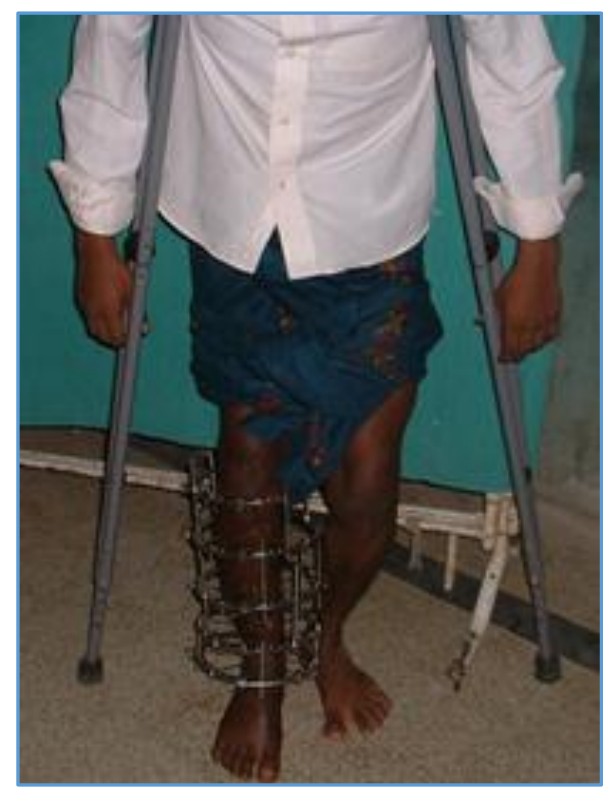




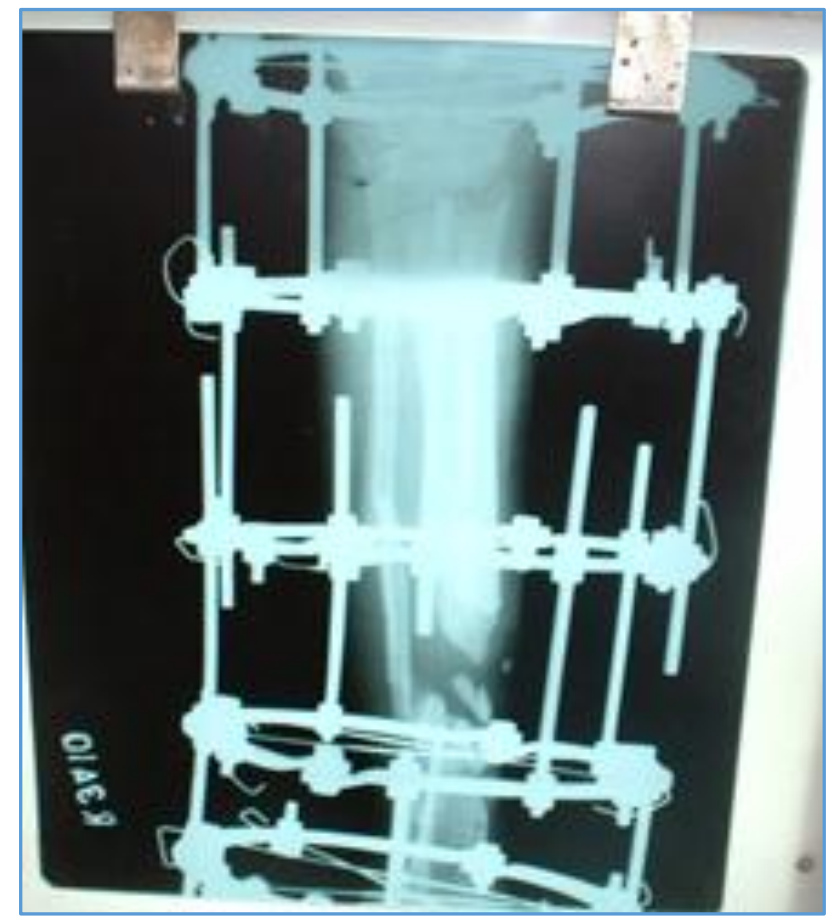

Post Op

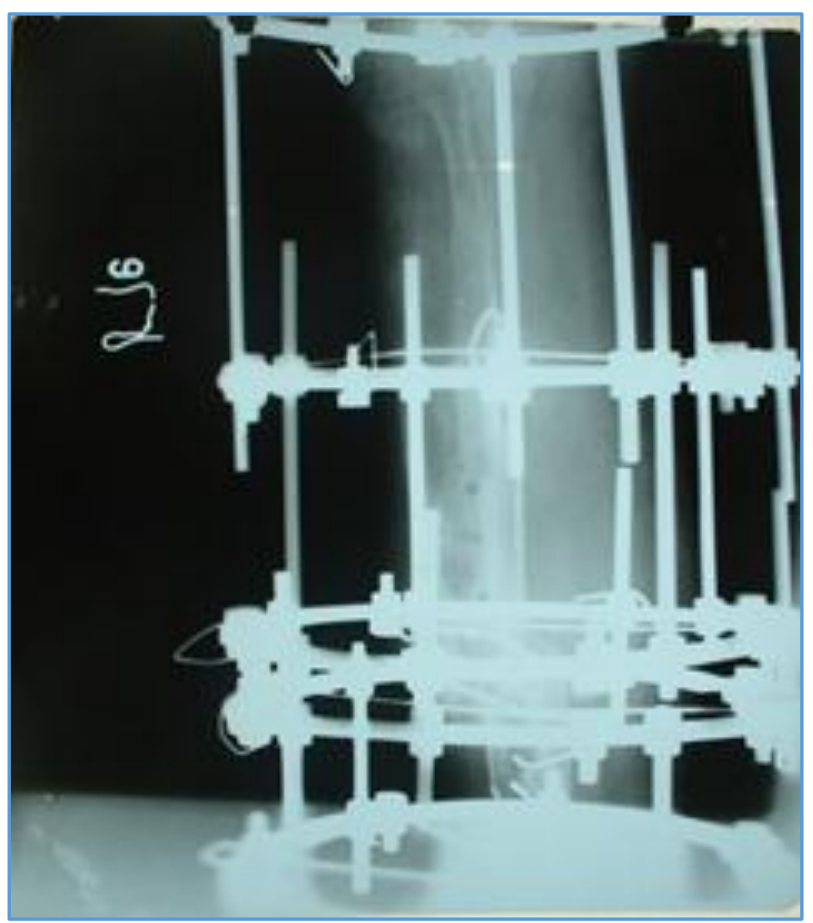

Fracture United

\section{Complications}

18 patients developed pin-tract infections at some point of time during treatment. Ten patients developed Grade II pintract infection which was successfully treated by oral antibiotics and local antibiotic injections. At the time of last follow-up, there were no cases of ring sequestrum. None of the patients developed any premature consolidation. However, delayed consolidation occurred in three cases where corticotomy was done in the distal tibial metaphysis. The rate of distraction was reduced and later bone formation was adequate. One patient developed bleeding from the corticotomy site 2 months after surgery. Hence, distraction was stopped, thereafter union was attained with a shortening of $3 \mathrm{~cm}$. At the time of commencement of treatment, 12 patients had equinus deformity of the ankle and stiffness of the knee due to immobilisation in POP cast or in external fixator. 8 cases required metatarsal $\mathrm{K}$ wire and half-ring to correct the equinus deformity. At final followup, there were 5 patients who had residual equinus contracture. One patient developed re-fracture 3 months after union. He was treated with 4-ring frame for 5 months and attained union thereafter.

\section{DISCUSSION}

In this study, road traffic accidents accounted for $90 \%$ of injuries while $10 \%$ were due to domestic accidents and falls while a similar study by Farmanullah.(5) in Pakistan revealed that the cause of initial trauma was road traffic accidents in $46.55 \%$, firearm injury in $39.65 \%$ and a simple fall in $13.79 \%$. In our study, most of the injuries had resulted in considerable soft tissue injury which resulted in some of them being classified as nonunion even before the mandatory six-month period.

In our study, the mean duration for union with Ilizarov ring fixator for infected non-union of tibia was 33 weeks (12-60 weeks) which was lesser than (6 months to 31 months) that reported by Paley et al.(1) Khan et al(6) had a mean time to union of 8 (range, 3-31) months in his study. Union was achieved in $92 \%$ of the patients which was more than that reported by Cattaneo R(3), Maini L(7), Hosny $\mathrm{G}^{(8)}$ and Dendrinos GK(9) in their respective studies.

Our study had 3 cases of infected non-union with less than $1 \mathrm{~cm}$ bone loss which was treated with corticotomy and distraction combined with debridement and acute docking. There were 22 cases of infected non-union with more than 1 $\mathrm{cm}$ bone loss of which 5 cases required bone transport and 17 cases required corticotomy and distraction combined with debridement and acute docking. Trifocal osteosynthesis was not employed in our study.

Cattaneo and Catagni(3) have not recommended the use of bone grafts and have treated 3 failed tibiae by reapplication of the apparatus and compression successfully. Maini L et al(7) in their series of 30 cases observed that $10 \%$ of cases required bone grafting at the docking site. Hosny $\mathrm{G}$ et al(8) in their study of 11 cases of infected non-union tibia didn't require any additional procedure to achieve union. Dendrinos GK, Kontos S, Lyritsis $\mathrm{E}^{(9)}$ in their series of 28 patients observed that three patients $(11 \%)$ had a problem with union that was treated with augmentation with a bone graft.

Aaronovich et al(10) reported on 170 patients treated by Ilizarov technique for bony defects wherein excellent bone results were achieved in $68.9 \%, 28.7 \%$ had fair results while $2.4 \%$ had poor results. $74.8 \%$ had returned to work. Paley et al(1) studied 25 patients with tibial non-union with bone loss more than $1 \mathrm{~cm}$ and reported excellent bone results in $72 \%$, good bone result in $20 \%$, excellent and good functional results in $64 \%$ and $28 \%$ respectively. $60 \%$ of the patients returned to work during the treatment period. The ability to achieve an excellent bony result in even the worst of bony pathologic conditions does not guarantee a good functional result unless the patient has an acceptable neurovascular status. Farmanullah,(5) in his study graded patient results according to the ASAMI criteria wherein radiological results were reported excellent in $58.89 \%$ patients, good in $20.68 \%$, fair in $13.79 \%$ and poor in $8.62 \%$. The clinical results were found to 
be excellent in $56.89 \%$, good in $31.05 \%$, fair in $6.89 \%$ and poor in $5.17 \%$ of the patients. Another study by Khan et al (6) on 24 patients showed that functional outcome was excellent in 8 patients, good in 12 , fair in 2 , and failure in one, whereas bone union outcome was excellent in 6 patients, good in 14, fair in one, and poor in 2 patients.

A systematic review and meta-analysis of Ilizarov methods in treatment of infected non-unions by Yin et al(4) revealed an average bone union rate of $97.26 \%$. Among the 590 patients with infected non-union of tibia and femur who were included in the review, the poor rate in bone results and functional results was only $8 \%$ and $10 \%$ respectively which was similar to that obtained in our study. The rate of complications like refracture, malunion, infectious recurrence was only 4\%, 7\% and $5 \%$ respectively. Patil(2) in his study on 41 cases of infected femoral and tibial non-union reported a poor bone result in $14.7 \%$ and a poor functional result in $26.8 \%$.

In our study, bone grafting was not used for union. We treated all bone transport cases with freshening of fracture sites and compression. Our study compares favourably in almost all aspects with the other studies.

In our study, superficial pin-tract infection occurred in 18 cases which were managed with local and parenteral antibiotics. In cases where persistent pin-tract infection was present, patient was cured of the same once the apparatus was removed. Two patients had limb length discrepancy more than $1 \mathrm{~cm}$ which was acceptable to them. In our study, pain during treatment was almost universal in occurrence. It was seen more at sites of a pin-tract infection and at the distraction site. Pain interfered with ambulation in some patients. However, it was controlled with the use of various groups of non-steroidal anti-inflammatory drugs differing from patient to patient. Once the pain was relieved, almost all patients were made to ambulate. It was noted that pain tolerance and psychological profile of the patient was very important for the surgeon to decide on implementation of ambulation and physiotherapy. Two patients were engaged in light occupations, while on treatment.

The two failed cases of our series actually were due to poor compliance resulting in premature decision to remove the apparatus before it had served the purpose. Thus, patient selection criteria become one of the most important decisive factors in instituting this form of treatment.

Paley(1) reported persistent infection in 3 out of his 25 patients, deformity in 4 patients, limb shortening in 1 patient, limp in 4 cases and equinus in 5 cases. Complications encountered by Khan et al(6) in their study were pin-tract infection ( $\mathrm{n}=5)$, re-fracture $(\mathrm{n}=2)$, soft tissue impingement by Ilizarov rings $(n=2)$, recurrence of wound infection $(n=1)$, malunion ( $\mathrm{n}=1)$, and mortality $(\mathrm{n}=1)$ among the 24 cases they treated.

After follow-up, it was noted in our study that ankle movements never returned to normal while knee movements gradually recovered within 2-3 months except in 2 patients. This was probably due to soft tissue contracture following prolonged immobilisation prior to Ilizarov treatment and poor compliance to weight bearing and physiotherapy.

The soft tissue healing was notably accelerated by increased vascularity in the limb. Soft tissue defects which were left open quickly granulated and skin cover was obtained without skin grafting in all cases. Draining sinuses healed spontaneously on the application of the apparatus and restoration of stability. The stability provided by a properly applied Ilizarov frame was found to be excellent and thus aids in union.

\begin{tabular}{|c|c|c|c|c|c|c|}
\hline \multirow{2}{*}{ Study } & \multirow{2}{*}{$\begin{array}{l}\text { Mean Duration of } \\
\text { Treatment/Union }\end{array}$} & \multicolumn{2}{|c|}{ Final Status } & \multirow{2}{*}{$\begin{array}{c}\text { Failure } \\
\text { (\%) }\end{array}$} & \multirow{2}{*}{$\begin{array}{l}\text { Followup } \\
\text { Period }\end{array}$} & \multirow{2}{*}{$\begin{array}{l}\text { Mean Bone } \\
\text { Defect }\end{array}$} \\
\hline & & $\begin{array}{c}\text { Union } \\
(\%)\end{array}$ & $\begin{array}{c}\text { Infection } \\
(\%)\end{array}$ & & & \\
\hline $\begin{array}{l}\text { Cattaneo and } \\
\text { Catagni }(3)\end{array}$ & 23 weeks 4 days & 83 & nil & 17 & $\begin{array}{c}108 \text { weeks } 4 \\
\text { days }\end{array}$ & $4 \mathrm{~cm}$ \\
\hline Dendrinos GK(9) & 40 weeks & 82.14 & nil & 17.86 & 156 weeks & $6 \mathrm{~cm}$ \\
\hline Hosny. G(8) & 30 weeks & 90 & nil & 10 & NA & $3 \mathrm{~cm}$ \\
\hline Maini. L(7) & 21 weeks 3 days & 80 & 10 & 20 & 100 weeks & $2 \mathrm{~cm}$ \\
\hline Khan(6) & 32 weeks & 91.7 & 25 & 8.3 & 184 weeks & $3.3 \mathrm{~cm}$ \\
\hline Farmanullah(5) & - & 91.4 & - & 8.6 & 52 weeks & $2.9 \mathrm{~cm}$ \\
\hline Shahid(11) & 46 weeks & 100 & - & nil & 164 weeks & - \\
\hline Present study & 33 weeks & 92 & 4 & 8 & $\begin{array}{c}102 \text { weeks and } \\
4 \text { days }\end{array}$ & $3 \mathrm{~cm}$ \\
\hline
\end{tabular}

\section{CONCLUSION}

Non-union presents a therapeutic challenge to the orthopaedic surgeon. It is thus concluded from our study that when traditional methods of managing these non-unions fail, Ilizarov technique provides excellent results for majority of the patients by allowing early function of the limb resulting in adequate stimulus for soft tissue and bone healing. Functional loading of the extremity helps prevent and treat disuse osteoporosis and soft tissue dystrophy that many of these patients may develop due to prolonged periods of non-weight bearing. Patient motivation is essential to initiate physiotherapy and functional use of the limb from the first week after application of the fixator for successful treatment. But it is also to be borne in mind that proper selection of patients by avoiding extremes of age, and assessing compliance by the patients is essential for the successful application of this technique.

\section{ACKNOWLEDGEMENT}

The authors are deeply indebted to Dr. C S Vikraman, Professor and Head, Department of Orthopaedics, Government Medical College, Thiruvananthapuram for his guidance throughout the study. 


\section{REFERENCES}

1. Paley D, Catagni AM, Argnani F, et al. Ilizarov treatment of tibial non-unions with bone loss. Clin Orthop 1989;241:146-65.

2. Patil S, Montgomery R. Management of complex tibial and femoral nonunion using the Ilizarov technique, and its cost implications. J bone Jt surgery 2006;88(7):928-32.

3. Cattaneo R, Catagni M, Johnson EE. The treatment of infected non-unions and segmental defects of the tibia by the method of Ilizarov. Clin Orthop Relat Res 1992;280: 143-52.

4. Yin P, Ji Q, Li T, et al. A systematic review and meta-analysis of Ilizarov methods in the treatment of infected nonunion of tibia and femur. PLoS One 2015;10(11):e0141973.

5. Farmanullah, Khan MS, Awais SM. Evaluation of management of tibial non-union defect with Ilizarov fixator. J Ayub Med Coll Abbottabad 2007;19(3):34-6.

6. Khan MS, Rashid H, Umer M, et al. Salvage of infected nonunion of the tibia with an Ilizarov ring fixator. J Orthop Surg (Hong Kong) 2015;23(1):52-5.
7. Maini L, Chadha M, Viswanath J, et al. The Ilizarov method in infected nonunion of fractures. Injury 2000;31(7):50917.

8. Hosny G, Shawky MS. The treatment of infected non-union of the tibia by compression-distraction techniques using the Ilizarov external fixator. Int Orthop 1998;22(5):298302.

9. Dendrinos GK, Kontos S, Lyritsis E. Use of Ilizarov technique in the treatment of non-union of the tibia associated with infection. J Bone Jt Surg 1995;77(6):83546.

10. Aaronovich A, V S, Payeuski S. Rehabilitation by Ilizarov technique of patients with bony defects of the tibia complicated by chronic osteomyelitis. In: Experimental, theoretical and clinical aspects of transosseous osteosynthesis developed in KNIIEKOT Institute. 2nd International Conference, Kurgan, Russia. Kurgan 1986:p 74. 